This is the final peer-reviewed accepted manuscript of

Ruiz, Karina B.; Khakimov, Bekzod; Engelsen, Soren B.; Bak, Soren; Biondi, Stefania; Jacobsen, Sven-Erik: Quinoa seed coats as an expanding and sustainable source of bioactive compounds: An investigation of genotypic diversity in saponin profiles. INDUSTRIAL CROPS AND PRODUCTS 104. ISSN 0926-6690

DOI: $10.1016 / j . i n d c r o p .2017 .04 .007$

The final published version is available online at:

http://dx.doi.org/10.1016/i.indcrop.2017.04.007

Rights / License: The terms and conditions for the reuse of this version of the manuscript are specified in the publishing policy. For all terms of use and more information see the publisher's website. 


\title{
Quinoa seed coats as an expanding and sustainable source of bioactive compounds: An investigation of genotypic diversity in saponin profiles
}

\author{
Karina B. Ruiz ${ }^{\mathrm{a}, 1}$, Bekzod Khakimov ${ }^{\mathrm{b}, \mathrm{c}, 1}$, Søren B. Engelsen ${ }^{\mathrm{c}}$, Søren Bak ${ }^{\mathrm{b}}$, Stefania Biondi ${ }^{\mathrm{a}}$, \\ Sven-Erik Jacobsen ${ }^{\mathrm{b}, *}$ \\ a Dipartmento di Scienze Biologiche, Geologiche e Ambientali (BiGeA), Università degli Studi di Bologna, Via Irnerio 42, 40126, Bologna, Italy \\ b Department of Plant and Environmental Sciences, Faculty of Science, University of Copenhagen, Hoejbakkegaard Alle 13, DK, 2630 Taastrup, Denmark \\ ${ }^{\mathrm{c}}$ Department of Food Science, University of Copenhagen, Rolighedsvej 26, DK-1958 Frederiksberg, Denmark
}

\section{A R T I C L E I N F O}

Keywords:

Chenopodium quinoa

Quinoa waste-product

Seed coat

Triterpenoids

Saponins

\begin{abstract}
A B S T R A C T
Saponins (SAPs) are a diverse family of plant secondary metabolites and due to their biological activities, SAPs can be utilised as biopesticides and as therapeutic compounds. Given their widespread industrial use, a search for alternative sources of SAPs is a priority. Quinoa (Chenopodium quinoa Willd) is a valuable food source that is gaining importance worldwide for its nutritional and nutraceutical properties. SAPs from quinoa seed coats could represent a new sustainable source to obtain these compounds in high quantities due to the increasing production and worldwide expansion of the crop. This research aims to characterise saponins of seed coat waste products from six different quinoa varieties for their potential use as a saponin source. Gas chromatography (GC)- and Liquid chromatography (LC)- with mass spectrometry (MS) were applied for qualitative and relative quantitative analysis of saponins. GC-MS led to the identification of three main aglycones, oleanolic acid (Ole), hederagenin (Hed), and a phytolaccagenic acid (Phy), while LC-MS enabled characterization of 24 SAPs with varying sugar moieties. Hed was the most abundant aglycone, followed by Phy and Oledepending on the genotype. Saponin distribution and relative abundances are discussed in the light of genotype provenance and agronomic features. Improved knowledge on the phytochemicals present in quinoa varieties might help in finding valuable and sustainable uses for quinoa SAPs in agroindustry as biopesticides as well as in the production of food and pharmaceuticals.
\end{abstract}

\section{Introduction}

Currently, the major industrial source of SAPs is the bark of quillay (Quillaja saponaria Molina) accounting for $80 \%$ of the world market (San Martín, 2000). Unfortunately, the increasing commercial use of quillay SAPs is causing damage to Chilean forests (San Martín et al., 2000; Schlotterbeck et al., 2015). In the pharmaceutical industry, SAPs are used in the synthesis of hormones, contraceptives, anti inflammatories, expectorants, and diuretics (Vincken et al., 2007; Augustin et al., 2011). In addition, SAPs have found wide application in food and cosmetic production (Price et al., 1987; Sparg et al., 2004). In agriculture, SAPs have potential as biopesticides and growth promoters (Andresen and Cedergreen, 2010; Andresen et al., 2015). For example, molluscicidal and vermicidal activity has been reported in complex mixtures of SAP derivatives obtained from alkali treated quinoa seed coats (San Martín et al., 2008) and from SAP rich by products of tea oil production (Potter et al., 2010). Increased consumer demand for natural products with beneficial physico chemical (e.g., surfactant) and biological (e.g., biocidal, antimicrobial) properties makes steroidal and triterpenoid SAPs promising compounds for industrial applications.

Triterpenoid SAPs are a diverse group of compounds characterized by the presence of a triterpenoid aglycone backbone $\left(\mathrm{C}_{30} \mathrm{H}_{48}\right)$ with one or more sugar moieties attached to them via glycosidic and/or ester bonds (Khakimov et al., 2016b). Triterpenoid SAPs are ubiquitous in the plant kingdom (Sparg et al., 2004; Vincken et al., 2007). Triterpe noid aglycones found in plants include dammaranes, tirucallanes, oleananes, lupanes, hopanes, ursanes, taraxasteranes, cycloartanes, lanostanes, cucurbitanes, and steroids (Vincken et al., 2007). Biosynth esis and heterogeneity of SAPs depend on plant species and tissue type (Augustin et al., 2011). Moreover, environmental, agronomic factors as well as post harvest treatments, such as storage and processing seem to influence SAP composition of plants (Fenwick et al., 1991; Yoshiki

\footnotetext{
Abbreviations: SAPs, saponins; Ole, oleanolic acid; Phy, phytolaccagenic acid; Hed, hederagenin; GC, Gas Chromatography; LC, Liquid Chromatography; MS, Mass Spectrometry

* Corresponding author.

E-mail address: seja@plen.ku.dk (S.-E. Jacobsen). 1 These authors contributed equally to this paper.
} 
et al., 1998; Szakiel et al., 2011). Even though some research has been devoted to reveal the relationship between biological properties and chemical structure (Dini et al., 2001a,b; Francis et al., 2001; Güclü Üstündağ and Mazza, 2007; Khakimov et al., 2012), this aspect deserves further investigation.

In foods, SAPs may have a bitter and astringent taste depending on chemical structure, and consequently SAP levels in food products are reduced to decrease bitterness (Price et al., 1987; Gómez Caravaca et al., 2014). This is done through dehulling and washing of seeds, or by using so called sweet varieties with low SAP levels as in the case of quinoa (Ward, 2000; Dini et al., 2002). Quinoa (Chenopodium quinoa Willd) has become an extremely popular food in the last 20 years, especially in Europe and North America, due to the increased interest in vegetarian diets, its high nutritional quality, and the increasing number of people with gluten intolerance and celiac disorder (Rubio Tapia et al., 2009; Abugoch, 2009; Vega Gálvez et al., 2010).

Quinoa cultivation continues to expand worldwide, and the potential of quinoa in the food and healthcare sector is huge (Bazile et al., 2016; Jacobsen, 2003). Therefore, it is of high relevance to gain further knowledge on the SAP profiles of various quinoa varieties. It has been shown that SAP content of quinoa is mainly genotype dependent (Ward, 2000; Miranda et al., 2014). The major part of SAPs are present in the outer layers of the seed, and protect it from pests and herbivores (birds and insects) and microorganisms (Ridout et al., 1991; Abugoch, 2008). When properly handled to remove the bitter SAPs, which are the major anti nutritional factors, quinoa seeds have a mild flavour (Maradini et al., 2015). Compared to wheat, quinoa seed has higher protein content, but especially a more favourable amino acid profile (Repo Carrasco et al., 2003; Stikic et al., 2012). Quinoa has higher levels of energy, calcium, phosphorus, iron, dietary fiber and B vitamins than cereals (Abugoch, 2009). In addition to its nutritional profile, new targets in research are focused on quinoa by products in order to add value to its secondary metabolites, such as the SAPs that are removed prior to consumption and are, therefore, a waste product.

Bitter varieties of quinoa contain more SAPs (4.7 $11.3 \mathrm{~g} \mathrm{~kg}^{-1}$ dry matter) than sweet varieties $\left(0.20 .4 \mathrm{~g} \mathrm{~kg}^{-1} \mathrm{dry}\right.$ matter) (Mastebroek et al., 2000), thus they are more widely cultivated (San Martín et al., 2008; Stuardo and San Martín, 2008). The coat represents about $812 \% \mathrm{w} / \mathrm{w}$ of the quinoa seed and is the main storage tissue of SAPs (up to $86 \%$ of the total amount in seeds) (Ando et al., 2002). In total more than 30 SAPs have been identified from quinoa plants that possess mainly five different triterpenoid aglycones including Ole, Hed, Phy, and Serjanic acid (SA) (Mastebroek et al., 2000; Dini et al., 2001a,b, 2002; Zhu et al., 2002; Kuljanabhagavad et al., 2008; Kuljanabhagavad and Wink, 2009). The major sugar moieties of SAPs are glucose, arabinose, galactose, glucuronic acid, xylose, and rhamnose (Woldemichael and Wink, 2001; Zhu et al., 2002). Recently published genome sequencing of quinoa allowed the identification of the tran scription factor that is high likely to control the triterpenoid saponins synthesis in seeds (Jarvis et al., 2017). The finding is expected to ease future research on selection for sweet varieties of quinoa. In general, the high genetic variability in quinoa represents a precious resource, which can be exploited for selecting and breeding cultivars adapted to the most diverse soil and climatic conditions (Zurita Silva et al., 2014).

The present study reports, for the first time, the results of a comparative analysis of SAP profiles in powdered seed coats, rather than whole seeds of six different varieties of quinoa originating from Bolivia or selected and bred in Denmark. The main objective of the study was to screen a complexity and relative amounts of SAPs as well as their corresponding triterpenoid aglycones backbones from the quinoa seed coat waste products using comprehensive GC MS and LC MS/MS analysis.
Table 1

An overview of quinoa seed samples, harvested in 2014, investigated in this study.

\begin{tabular}{|c|c|c|c|c|c|}
\hline Variety & Acronym & Origin & $\begin{array}{l}\text { Place of Cultivation } \\
\text { (Lat;Long) }\end{array}$ & Quality & $\begin{array}{l}\text { Seed } \\
\text { colour }\end{array}$ \\
\hline Sample 1 & $\mathrm{P} 1$ & Bolivia & Uyuni (BO) & bitter & white \\
\hline Sample 2 & $\mathrm{P} 2$ & $(\mathrm{BO})$ & $20^{\circ} 28^{\prime} 12^{\prime \prime} \mathrm{S}$ & bitter & white \\
\hline Real & QR & & $66^{\circ} 48^{\prime} 50^{\prime \prime} \mathrm{W}$ & bitter & white \\
\hline Titicaca & $\mathrm{Ti}$ & $\begin{array}{l}\text { Denmark } \\
\text { (DK) }\end{array}$ & Taastrup (DK) & bitter & $\begin{array}{l}\text { light } \\
\text { brown }\end{array}$ \\
\hline Puno & $\mathrm{Pu}$ & & $55^{\circ} 40^{\prime} 13.2^{\prime \prime} \mathrm{N}$ & bitter & $\begin{array}{l}\text { light } \\
\text { yellow }\end{array}$ \\
\hline Vikinga & Q124 & & $12^{\circ} 18^{\prime} 13.4^{\prime \prime E}$ & sweet & $\begin{array}{l}\text { light } \\
\text { brown }\end{array}$ \\
\hline
\end{tabular}

\section{Materials and methods}

\subsection{Seed material}

Seeds were collected in 2014 from six different varieties of quinoa (Table 1). QR is a Real type variety originating from Bolivia; P1 and P2 are mixed samples of Bolivian material. Titicaca (Ti) and Puno (Pu) are registered varieties that were selected and bred in Denmark from varieties originated in southern Chile and Peru (Jacobsen, 1998; Adolf et al., 2012). Q124 is a Danish variety bred for low SAP content, now registered under the name Vikinga. The seed coats powder of Real varieties was obtained from seeds harvested in Bolivia, while Danish varieties were obtained from seeds harvested in Denmark.

\subsection{Sample preparation}

Twenty five mg DW of the outer layer of quinoa seeds (obtained after mechanical dehulling using a mill) were powdered and extracted following the procedure described by Khakimov et al. (2016a,b) with some modifications, using $80 \%$ methanol in the ratio of $25: 1(\mathrm{w} / \mathrm{v})$. The mixture was vortexed for $30 \mathrm{~s}$, incubated at $70{ }^{\circ} \mathrm{C}$ for $3 \mathrm{~h}$ with agitation at $1400 \mathrm{rpm}$ using a ThermoMixer F2.0 (Eppendorf, Hørsholm, Denmark), and cooled to room temperature. Extracts were then vortexed for $30 \mathrm{~s}$, and centrifuged at $16 \mathrm{~kg}$ for $10 \mathrm{~min}$. In order to identify the triterpenoid aglycones and characterise sugar moieties of SAPs, the supernatant was separated into aliquots as follows: $0.1 \mathrm{~mL}$ for LC MS/ MS analysis; $0.37 \mathrm{~mL}$ for $\mathrm{HCl}$ (acidic) hydrolysis and $0.37 \mathrm{~mL}$ for basic $(\mathrm{NaOH})$ hydrolysis based GC MS analysis. Basic hydrolysis was applied prior to GC MS in order to cleave sugar moieties linked via ether bonds, while the acidic hydrolysis removed sugar moieties linked via both ether and glycosidic bonds. The general procedure for SAP extraction is summarized in Fig. 1.

Aliquots consisting of $0.37 \mathrm{~mL}$ of supernatants were completely dried in a ScanVac (Labogene, Lynge, Denmark) operating at $45{ }^{\circ} \mathrm{C}$ and $200 \mathrm{~g}$ for $23 \mathrm{~h}$. For the acidic hydrolysis, $0.5 \mathrm{~mL}$ of $2 \mathrm{M} \mathrm{HCl}$ was added, the mixture was vortexed for $30 \mathrm{~s}$ and then incubated at $100{ }^{\circ} \mathrm{C}$ for $1.5 \mathrm{~h}$ in the ThermoMixer (1400 rpm). The mixture was cooled to room temperature. For basic hydrolysis, $0.5 \mathrm{~mL}$ of $2 \mathrm{M} \mathrm{NaOH}$ was added to the dried aliquots of $0.37 \mathrm{~mL}$ supernatant; the mixture was vortexed for $30 \mathrm{~s}$ and incubated at $25^{\circ} \mathrm{C}$ for $1.5 \mathrm{~h}$ with mixing at $1400 \mathrm{rpm}$ as described above. Thereafter, $0.1 \mathrm{~mL}$ of $12 \mathrm{M} \mathrm{HCl}$ was added to adjust the $\mathrm{pH} \leq 2$. Both acidic and basic extracts were then transferred to fresh $15 \mathrm{~mL}$ Falcon tubes. Free aglycones, released by hydrolysis, were extracted by addition of diethyl ether at an extract:ether ratio of 1:4 (v/v). This procedure was repeated twice and the combined ether fractions were washed with MilliQ water (ether:water, 2:1, v/v) in order to remove the residual acid or base. The washed ether fraction was transferred into a new $15 \mathrm{~mL}$ tube, dried under fume hood and re suspended in $0.25 \mathrm{~mL}$ of $80 \%$ methanol. After centrifugation (16k g for $3 \mathrm{~min}$ ) of the final methanol extracts, $0.1 \mathrm{~mL}$ aliquot was used for LC MS/MS and $0.05 \mathrm{~mL}$ was used for GC MS. Prior to GC MS, samples 


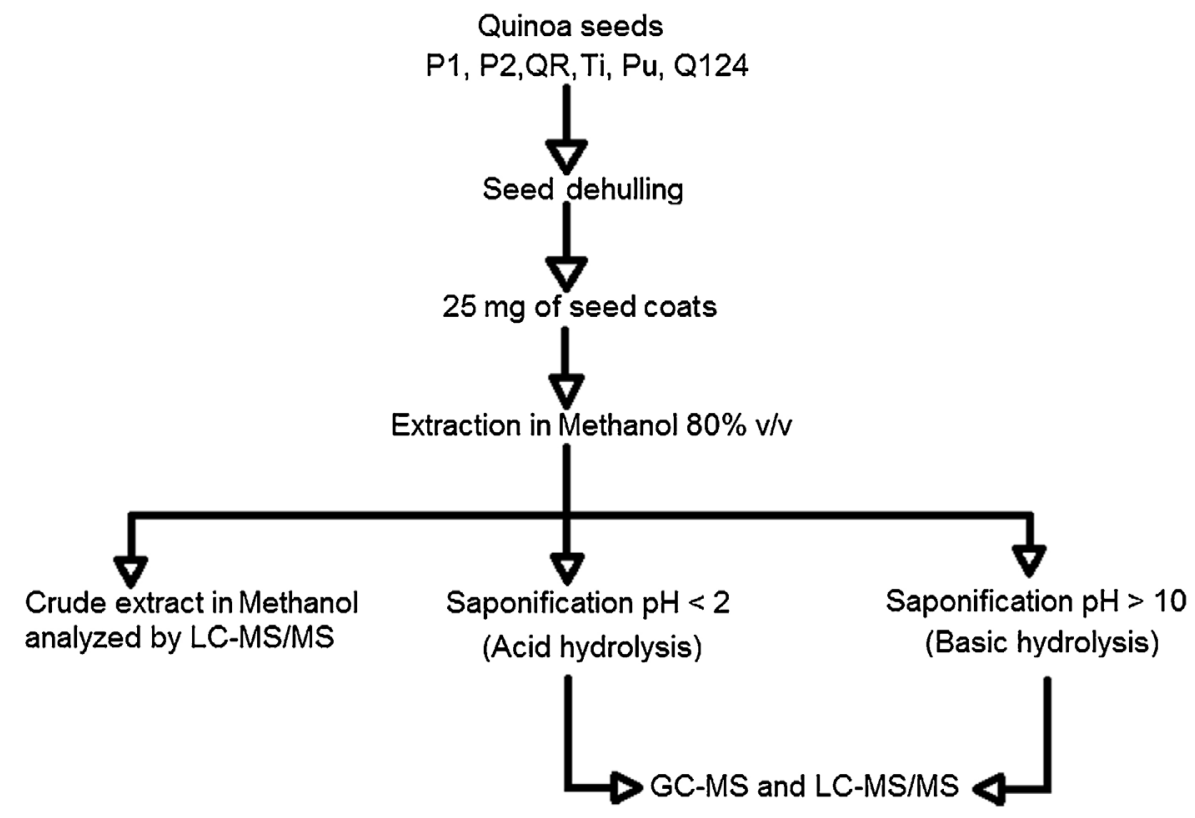

Fig. 1. Schematic protocol to determine SAP contents by two different chromatographic approaches after acidic and basic hydrolysis of powdered quinoa seed coats.

were dried in $0.2 \mathrm{~mL}$ glass inserts using a ScanVac $\left(2.5 \mathrm{~h}\right.$ at $40{ }^{\circ} \mathrm{C}, 100$ $\mathrm{rpm})$. Dried samples were stored at $-20^{\circ} \mathrm{C}$ until derivatization.

\subsection{GC MS analysis of samples}

Dried samples were derivatized using trimethylsilylation as described by Khakimov et al. (2013). Thirty $\mu \mathrm{L}$ of trimethylsilyl cyanide (TMSCN, Sigma Aldrich, St. Louis, USA) were added to each sample and agitated at $750 \mathrm{rpm}$ for $50 \mathrm{~min}$ at $45{ }^{\circ} \mathrm{C}$. All steps involving sample derivatization and injection were automated using a MultiPurpose Sampler (Gerstel, Mülheim an der Ruhr, Germany). The GC MS system consisted of an Agilent 7890A GC and an Agilent 5975C series MSD. GC separation was performed on a Phenomenex ZB 5MSi column $(30 \mathrm{~m} \times$ $250 \mu \mathrm{m} \times 0.25 \mu \mathrm{m}$ ). A derivatized sample volume of $1 \mu \mathrm{L}$ was injected into a split/splitless inlet at $320{ }^{\circ} \mathrm{C}$ using a pulsed splitless mode at an injection pulse pressure of 20 psi until 2 min of splitless time; purge flow to split vent after splitless time and septum purge flow were set at 15 and $3 \mathrm{~mL} \min ^{-1}$, respectively. Hydrogen was used as carrier gas, at a constant flow rate of $1.2 \mathrm{~mL} \mathrm{~min}^{-1}$. The GC oven program was set as follows: initial temperature $40{ }^{\circ} \mathrm{C}$, equilibration time $2.0 \mathrm{~min}$, heat up to $270{ }^{\circ} \mathrm{C}$ at a rate of $12{ }^{\circ} \mathrm{C} \mathrm{min}-1$, then heat at a rate of $6{ }^{\circ} \mathrm{C} \mathrm{min}{ }^{-1}$ until $320^{\circ} \mathrm{C}$ and hold for $5 \mathrm{~min}$. Mass spectra were recorded in the range of 50 $500 \mathrm{~m} / \mathrm{z}$ with a scanning frequency of 3.2 scans s $^{-1}$, and the MS detector was switched off during the $6 \mathrm{~min}$ of solvent delay time. The transfer line, ion source, and quadrupole temperatures were set at 290, 230 and $150{ }^{\circ} \mathrm{C}$, respectively. The mass spectrometer was tuned according to the manufacturer's recommenda tion by using perfluorotributylamine (PFTBA). The aglycones were identified by comparing retention time (RT) and Electron Impact Mass Spectrum (EI MS) of authentic standards of Hed and Ole (Fluka, Sigma Aldrich).

\subsection{LC MS/MS analysis of samples}

In order to determine SAP levels, LC MS/MS analysis was performed as described by Augustin et al. (2012) using an Agilent 1100 Series LC device (Agilent Technologies, Inc., USA), equipped with a Gemini NX column, $150 \mathrm{~mm}$ length and $3.5 \mathrm{~mm}$ diameter (Phenomen ex, Torrance, USA) operated at $35^{\circ} \mathrm{C}$ and coupled to a Bruker HCT Ultra ion trap mass spectrometer (Bruker Daltonics). The samples $(0.1 \mathrm{~mL}$ each) were transferred into glass vials and diluted to $1.5 \mathrm{~mL}$ with $85 \%$ methanol for LC MS analysis. The mobile phases consisted of two eluents: water with $0.1 \%(\mathrm{v} / \mathrm{v})$ formic acid (A), and acetonitrile with $0.1 \%(\mathrm{v} / \mathrm{v})$ formic acid (B). The gradient was programmed as follows: 0 $1 \mathrm{~min}$, isocratic $12 \% \mathrm{~B} ; 133 \mathrm{~min}$, linear gradient $12 \%$ 80\% B; $3335 \mathrm{~min}$, linear gradient $80 \% 99 \% \mathrm{~B}$; $3538 \mathrm{~min}$, isocratic 99\% B; $3845 \mathrm{~min}$, isocratic $12 \% \mathrm{~B}$ at a constant flow rate of $0.2 \mathrm{~mL} \mathrm{~min}^{-1}$. The Bruker HCT Ultra ion trap mass spectrometer (Bruker Daltonics) was operated using electrospray ionization and $m / z$ ions were detected in a negative mode using tandem mass spectrometry. Qualitative analysis and visualization of LC MS/MS data were performed using the DataAnalysis 4.0 (Bruker Daltonics) software.

\subsection{Data analysis}

In order to calculate the GC MS peak areas of aglycones (relative concentrations), the raw GC MS data were processed by the PARAFAC2 as described previously (Khakimov et al., 2012). Relative concentrations of SAPs were calculated from the total ion current (TIC) chromatograms of the raw LC MS data. Prior to SAP profile comparison, the data was normalized using the 1 norm (division of each peak area by the sum of areas of all peaks detected in the same sample).

\section{Results}

A total of six different quinoa seed coat samples of varying origins and genetic backgrounds were analysed for their SAP profiles using GC MS and LC MS/MS prior to and after acid or basic hydrolysis.

\subsection{Identification of triterpenoid aglycones by GC MS}

GC MS analysis of acid hydrolysed samples revealed three major aglycones: Ole, Hed, and Phy. Serjanic acid (SA) was only detected in a neglectable amount in all quinoa varieties, thus it is outside the scope this paper to discuss it further. Ole and Hed were identified at level 1 (Sumner et al., 2007) using authentic standards, while Phy and SA were identified at level 2 using mass spectral and retention index comparison with data reported in the literature (Fig. 2A) (Gómez Caravaca et al., 2012; Medina Meza et al., 2016). Electron Ionization Mass Spectrum (EI MS) and Retention Indices [RIs] of all four triterpenoid aglycones are illustrated in Supplementary Fig. 1. The relative abundance of aglycones in each variety showed that Hed was the most abundant 
A

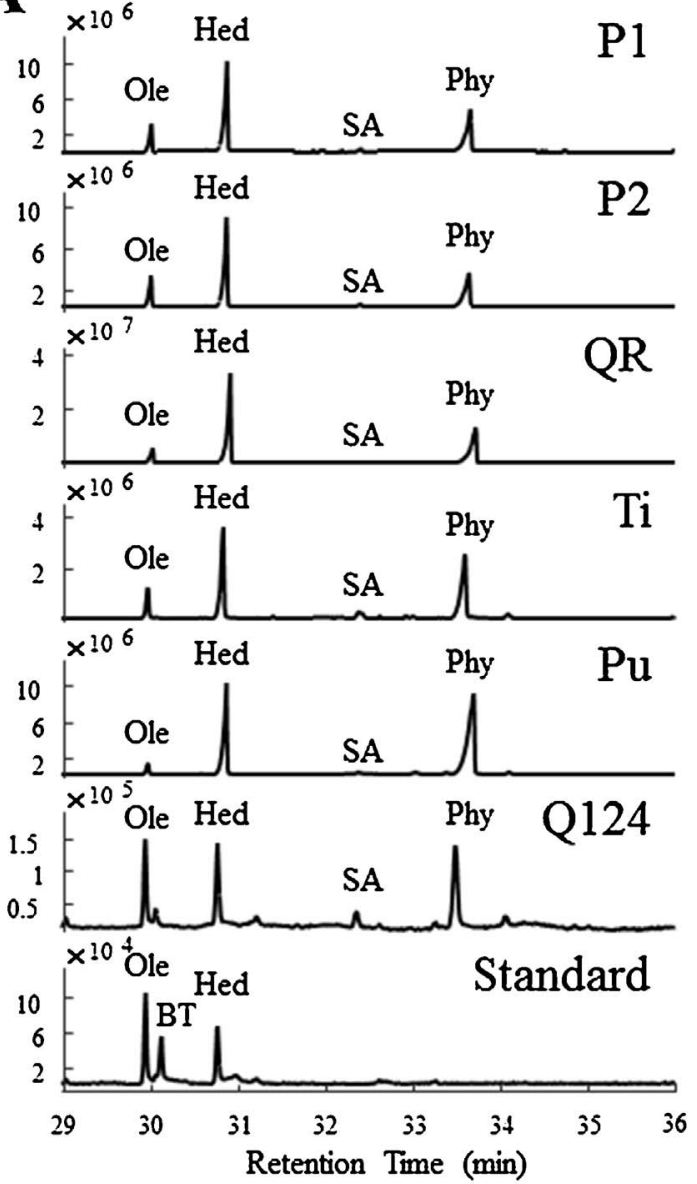

B
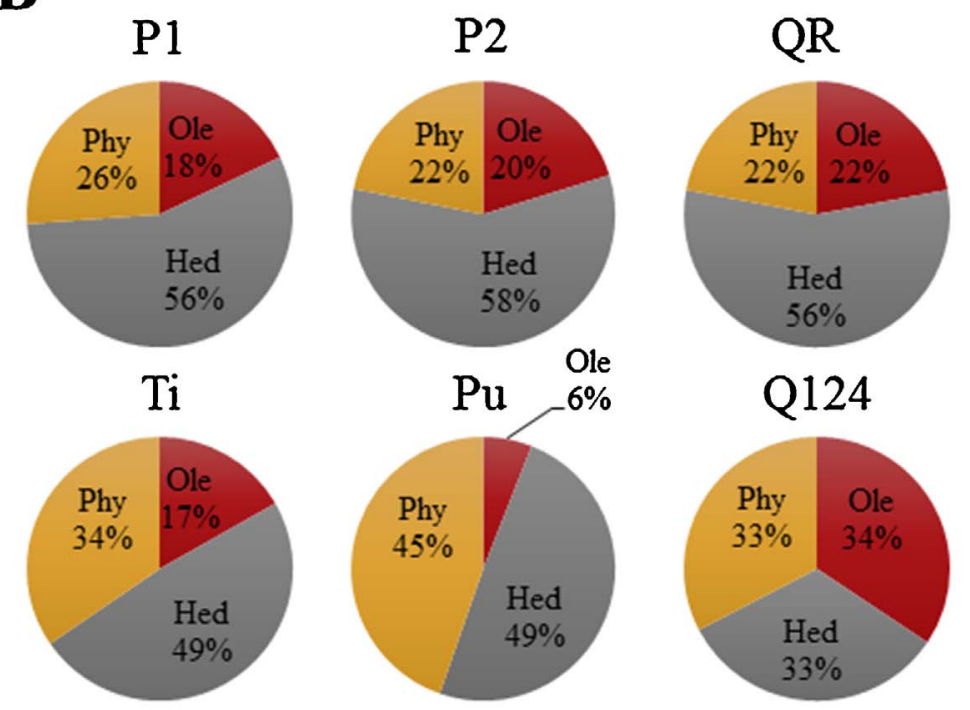

Q124
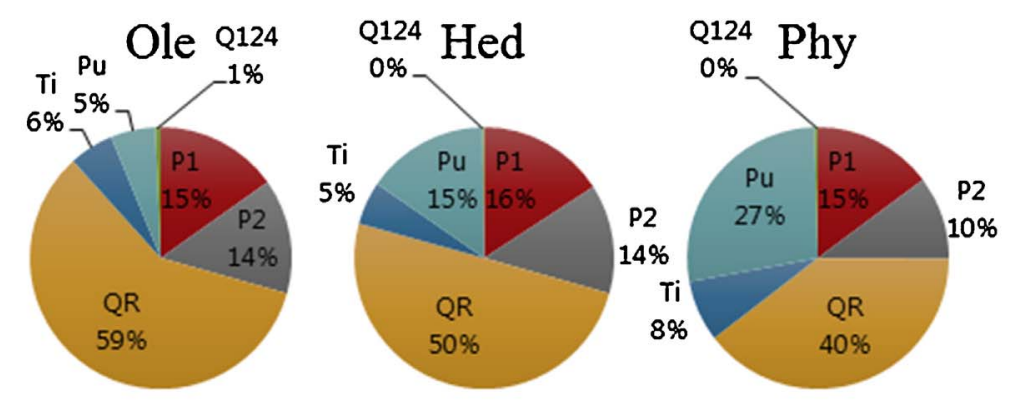

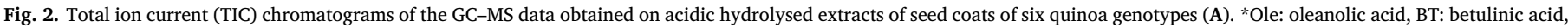

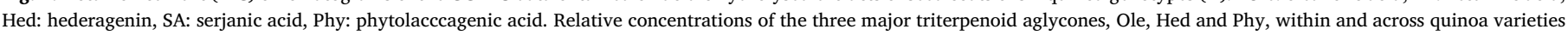
(B).

triterpenoid aglycone in all six quinoa samples, amounting to ca. 50\% of the triterpenes detected, except in Q124 where all three major sapogenins reached similar percentages (Fig. 2B). Relative concentrations of Ole and Phy were similar in P1, P2, and QR and ranged from 18 to $26 \%$ of the total aglycones (Fig. 2B). Phy increased to twice the amount of Ole (17\%) in Ti. In Pu, the percentage of Ole was detected at the lowest relative amount (6\%).

When the six quinoa samples were compared with respect to each of the three identified aglycones, QR exhibited the highest amounts (relative to the other varieties) of all three major aglycones, whereas Q124 had the lowest amounts (Fig. 2C). P1 and P2 showed 14 and 15\% relative concentrations of Ole, respectively, while $\mathrm{Pu}$ and $\mathrm{Ti}$ contained only 5 6\%; Q124 contained the lowest relative amount of this SAP (Fig. 2C). The relative concentration of Hed was similar in P1, P2 and Pu (14 $16 \%)$, whereas $\mathrm{Ti}(5 \%)$ and Q124 ( $<1 \%)$ showed lower amounts of this aglycone. The relative concentration of Phy in QR was $40 \%$, followed by $\mathrm{Pu}$ with 27\%, P1, P2 and Ti with 15, 10 and 8\%, respectively; in Q124, this SAP was below detection threshold.

GC MS analysis of the same quinoa extracts using basic hydrolysis showed a notable decrease in the amounts of Ole and Hed in P1, P2, QR and $\mathrm{Pu}$ (data not shown). This suggests that these quinoa samples mostly contain Ole and Hed based SAPs where sugar moieties are linked to the aglycones via a glycosidic bond.

\subsection{Saponin characterization by LC MS/MS analysis}

A total of 24 SAPs were tentatively characterized by LC MS/MS in the six quinoa seed coat samples (Table 2). The relative amounts of these SAPs in each sample are shown in Fig. 3. Tandem mass spectrometry data allowed us to interpret fragmentation patterns of SAPs, where mainly loss of a hexose (162 Da) and loss of an unknown adduct ion with a mass of 172 Da were observed. It is speculated that loss of the latter adduct ion from SAPs may derive from the acyl moiety (acyl $\mathrm{H}_{2} \mathrm{O}$ ), 3,5 dihydroxy 6 methyloctanoic acid, which is possibly conju gated to a hydroxyl group of the aglycone. Several saponins of Quillaja saponaria based on quillaic acid indeed possess 3,5 dihydroxy 6 methy loctanoic acid and their MS/MS spectra exhibit the loss of the same 172 Da adduct (Sun et al., 2003; Qin et al., 2006).

Three major SAPs, with three to four sugar moieties, showed an aglycone molecular weight (MW) of $472 \mathrm{Da}$, which is in agreement with the GC MS data in which Hed (472 Da) was found to be the most abundant aglycone in all quinoa samples. Seven putative SAPs, with two to four sugar moieties, showed an aglycone MW of $456 \mathrm{Da}$, in agreement with the GC MS data which identified Ole (456 Da) as one of the three main triterpenoids. Four SAPs, all containing three sugar moieties, showed an aglycone with MW of $500 \mathrm{Da}$, which was also in agreement with the GC MS data that allowed identification of SA with MW of 500 Da. Although it was not possible to determine the MW of Phy (516 Da) from the MS/MS experiment, it is speculated that the last seven putative SAPs, with two to three sugar moieties, correspond to Phy aglycone. However interpretation of such a fragmentation pattern that may result in $m / z$ ion at 440 Da remains scarce (Table 2). More over, two SAPs with an aglycone MW of 470 Da were detected and showed loss of three sugar moieties.

The genotype with the highest diversity in SAPs was Pu (20 peaks) followed by $\mathrm{P} 1>\mathrm{P} 2>\mathrm{QR}>\mathrm{Ti}\left(\begin{array}{lll}16 & 15 & \text { peaks}\end{array}\right)>\mathrm{Q} 124 \quad(10$ 
Table 2

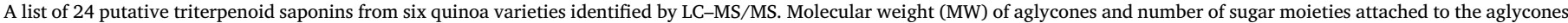

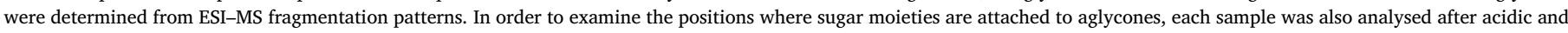
basic hydrolysis.

\begin{tabular}{|c|c|c|c|c|c|c|}
\hline \multirow[t]{2}{*}{ Peak No. } & \multirow{2}{*}{$\begin{array}{l}\text { RT } \\
(\min )\end{array}$} & \multirow[t]{2}{*}{ Aglycone MW (Da) } & \multirow[t]{2}{*}{ Mass spectral fragmentation pattern* } & \multirow[t]{2}{*}{ Quinoa genotypes } & \multicolumn{2}{|c|}{ Detection after hydrolysis** } \\
\hline & & & & & Acidic & Basic \\
\hline 1 & 13.3 & 472 & $967-162-162-172=471$ & P1; P2; QR; Ti; Pu; Q124 & nd & reduced \\
\hline 2 & 13.6 & 456 & $805-162-172=455$ & $\mathrm{P} 1 ; \mathrm{Ti} ; \mathrm{Pu}$ & nd & reduced \\
\hline 3 & 14.0 & 472 & $967-162-162-172=471$ & $\mathrm{QR} ; \mathrm{Pu}$ & nd & reduced \\
\hline 4 & 14.2 & 456 & $805-162-172=455$ & P2; QR; Ti; Pu & nd & nd \\
\hline 5 & 14.5 & 472 & $1129-3(162)-172=471$ & P1; P2; QR; Ti; Pu; Q124 & nd & reduced \\
\hline 6 & 15.1 & 470 & $1127-3(162)-172=469$ & P1; P2; QR; Ti; Pu; Q124 & nd & reduced \\
\hline 7 & 15.5 & 500 & $995-162-162-172=499$ & $\mathrm{Pu}$ & nd & reduced \\
\hline 8 & 16.0 & 500 & $995-162-162-172=499$ & P1; P2; QR; Ti; Pu; Q124 & nd & nd \\
\hline 9 & 17.1 & 500 & $1005-2(172)-162=499$ & P1; P2; QR; Ti; Pu; Q124 & nd & nd \\
\hline 10 & 18.1 & 456 & $951-2(162)-172=455$ & P1; P2; QR; Ti; Pu; Q124 & nd & nd \\
\hline 11 & 18.5 & 470 & $965-2(162)-172=469$ & $\mathrm{Pu}$ & nd & reduced \\
\hline 12 & 18.8 & 470 & $995-162-162-172=499$ & Ti; Pu; Q124 & nd & nd \\
\hline 13 & 19.3 & 456 & $789-162-172=455$ & P1; P2; QR; Ti; Pu; Q124 & nd & reduced \\
\hline 14 & 19.4 & 500 & $833-2(172)-162=499$ & $\mathrm{Ti} ; \mathrm{Pu}$ & nd & nd \\
\hline 15 & 20.3 & 456 & $988-3(162)-2(46)=455$ & P1; P2; QR; Ti; Pu & nd & nd \\
\hline 16 & 20.6 & 456 & $988-3(162)-2(46)=455$ & P1; P2; QR; Ti; Pu & nd & nd \\
\hline 17 & 21.1 & 456 & $988-3(162)-2(46)=455$ & P1; P2; QR; Ti; Pu; Q124 & nd & reduced \\
\hline $18^{\mathrm{a}}$ & 21.8 & 440 & $972-3(162)-2(46)=439$ & P1; P2; QR & nd & nd \\
\hline $19^{\mathrm{a}}$ & 22.4 & 440 & $972-3(162)-2(46)=439$ & P1; P2; QR; Pu & nd & nd \\
\hline $20^{\mathrm{a}}$ & 22.9 & 440 & $972-3(162)-2(46)=439$ & $\mathrm{Ti} ; \mathrm{Pu}$ & nd & nd \\
\hline $21^{\mathrm{a}}$ & 23.1 & 440 & $972-3(162)-2(46)=439$ & P1; P2; QR & nd & nd \\
\hline $22^{\mathrm{a}}$ & 23.5 & 440 & $972-3(162)-2(46)=439$ & $\mathrm{Pu} ; \mathrm{Q} 124$ & nd & nd \\
\hline $23^{\mathrm{a}}$ & 24.2 & 440 & $972-3(162)-2(46)=439$ & $\mathrm{P} 1 ; \mathrm{P} 2 ; \mathrm{QR}$ & nd & reduced \\
\hline $24^{\mathrm{a}}$ & 25.5 & 440 & $949-3(162)-1(46)=439$ & P1; P2; QR; Ti & nd & nd \\
\hline
\end{tabular}

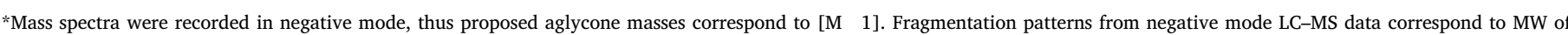

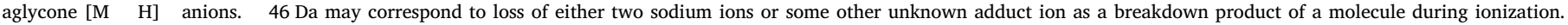

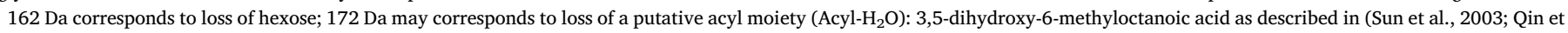

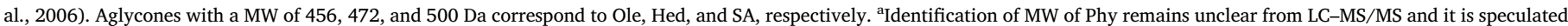

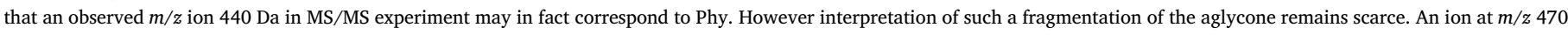

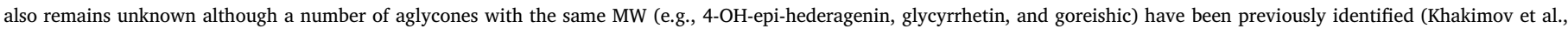
2012, 2013). ** nd: not detected after hydrolysis.

peaks). As shown in Table 2, putative SAPs 1, 5, 6, 8, 9 and 13 were found in all six quinoa genotypes. Peaks 8 and 9 displayed the highest relative percentage in all samples with Q124 showing the highest relative abundance in these two peaks. Peaks 18, 21 and 23 were detected only in samples P1, P2, and QR, while peak 7 and 11 were exclusively observed in Pu. Quinoa variety Q124 was the most different than other five varieties and lacked peaks 15 and 16 (Table 2; Fig. 3).

The LC MS/MS analysis of methanol extracts after acid or basic hydrolysis revealed a dramatic reduction in both the number and intensity of the putative SAP peaks (Table 2). This pattern was observed in all six samples. The hydrolytic process, in which the sugar moieties of SAPs are cleaved off, causes a loss of polarity, resulting in decreased ionization in ESI. Most of the SAP peaks disappeared after acid hydrolysis, while fewer peaks disappeared or were only reduced after mild basic hydrolysis (Table 2). This suggests that the investigated quinoa genotypes possess SAPs decorated with sugar moieties (e.g., glucose, cellobioside) attached to the triterpenoid aglycones either by glucosidic bond (e.g., C3 or C23 positions in Hed) or by ester (e.g., C28 positions in Hed) bond.

\section{Discussion}

This study reports the relative concentrations of aglycones (after saponification) and SAP profiles obtained by GC MS and LC MS/MS, respectively, from the seed coat powders of six different quinoa varieties. Three major aglycones identified in all six genotypes were Ole, Hed, and Phy. Several studies have identified these three aglycones as the major triterpenoid backbones in both bitter and sweet quinoa seeds (Mizui et al., 1990; Mastebroek et al., 2000; Woldemichael and Wink, 2001; Dini et al., 2001a,b, 2002; Zhu et al., 2002; Madl et al.,
2006; Verza et al., 2012). Similar to this study several authors have identified a fourth aglycone, SA, in seeds and other tissues of quinoa as being less abundant than the other triterpenoid aglycones (Dini et al., 2001a,b, 2002; Madl et al., 2006; Kuljanabhagavad et al., 2008; Medina Meza et al., 2016).

The most abundant aglycone detected in the six genotypes was Hed, followed by Phy, and Ole. As previously reported by Kuljanabhagavad et al. (2008), Hed is indeed present in quinoa seed, seed coats, flowers and fruits in high quantities. The relative proportions of triterpenoids changed depending on genotype. The samples consisting of Real type varieties (P1, P2, and QR) generally contained higher relative amounts of Hed, Ole, and Phy than other varieties which may account for their strong bitterness. In the Danish varieties $\mathrm{Ti}$ and $\mathrm{Pu}$, Phy represented a higher percentage than in other varieties. Phy and Ole were reported to be the most abundant aglycones in seeds of Ch. berlandieri and Phy was more concentrated in the seed coat than Ole (Lazo Vélez et al., 2016). While Pu and Ti had distinctly less Ole than other varieties, QR had the highest relative amount of this as well as of the other two aglycones. This difference may be associated with the strongly contrasting origins of these varieties, with QR belonging to the salares ecotype (from high altitudes and stressful environments in Bolivia) and the day length neutral varieties, bred in Denmark using Chilean Peruvian material, being better adapted to European environments (Christiansen et al., 2010; Jacobsen, 2015; Ruiz et al., 2016).

Bitterness of quinoa whole seed was associated to a high content of Phy (Medina Meza et al., 2016). Likewise, in this study we found Phy in the seed coat powder of all bitter varieties of quinoa, except in the sweet variety Q124. Moreover, relative amounts of Phy were much higher in Bolivian bitter varieties. In plants, Ole based SAPs may function as defence compounds against herbivores or pathogens 


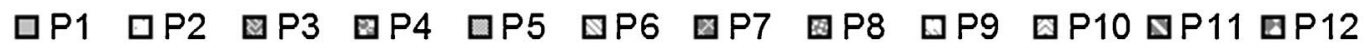

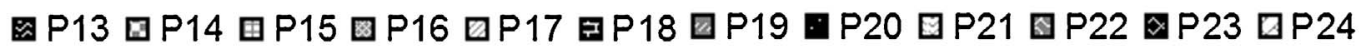
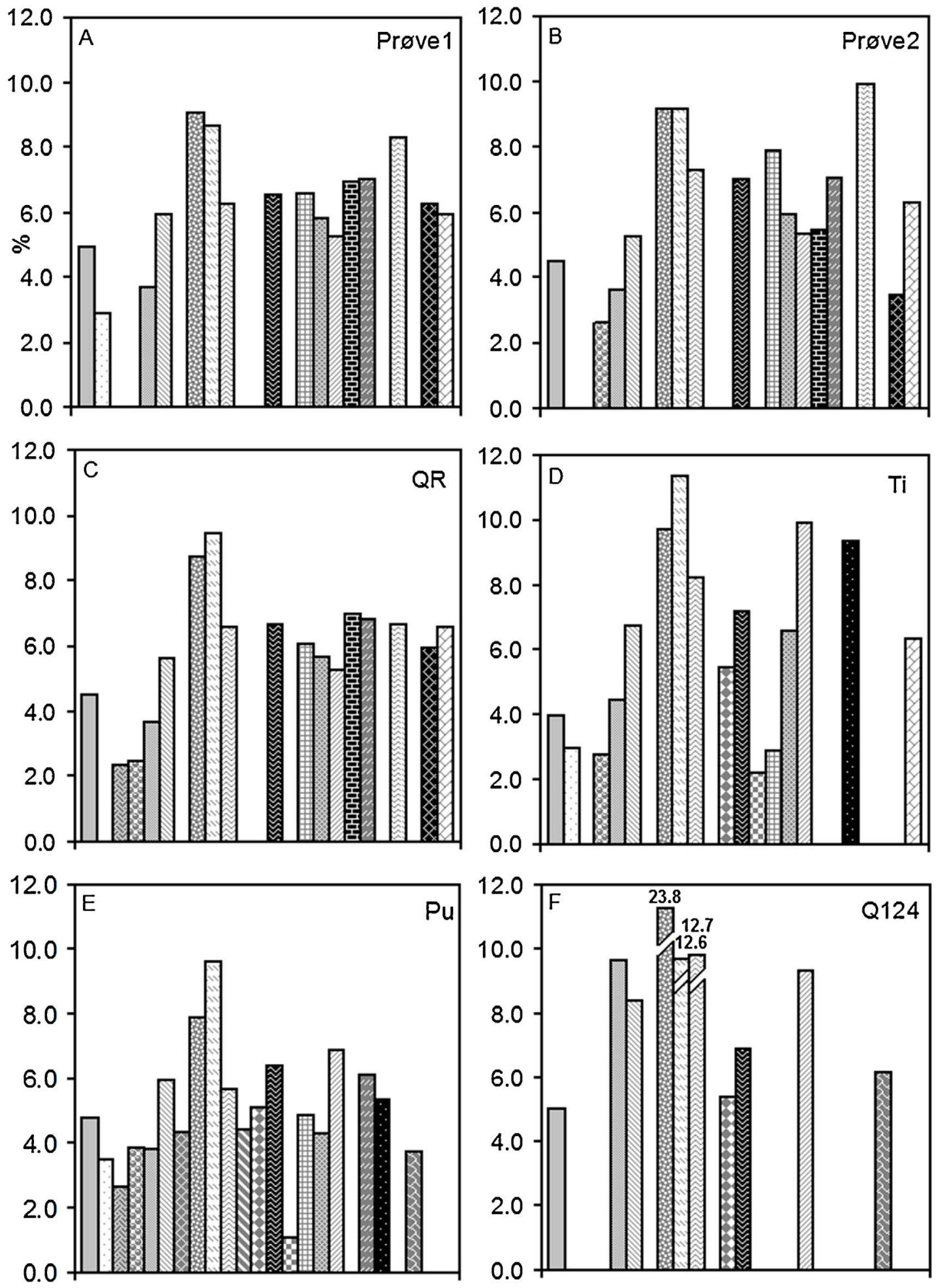

Peak number (1 to 24 )

Fig. 3. Relative percentage concentrations of the 24 SAPs tentatively identified by LC-MS/MS in the methanolic extract of seed coats of six different varieties of quinoa. (A) P1, (B) P2, (C) $\mathrm{QR},(\mathrm{D}) \mathrm{Ti},(\mathrm{E}) \mathrm{Pu}$, and (F) Q124. 
(Augustin et al., 2012), or as allelopathic agents (Szakiel et al., 2003; Pollier and Goossens, 2012). Free Ole can be also found in the epicuticular waxes of plants, preventing water loss and serving as a first defence barrier against pathogens (Kubo and Matsumoto, 1984). Woldemichael and Wink (2001) showed that glycosides of Ole and Hed from quinoa seed exhibited antifungal activity against Candida albicans. Stuardo and San Martín (2008) found high antifungal activity against Botrytis cinerea, one of the most important diseases of table grapes, in alkali treated quinoa saponins based on Phy (the most abundant), Hed and Ole.

A total of 24 putative SAPs were detected from seed coats of six quinoa varieties using LC MS/MS that depicted unique fragmentation patterns. Kuljanabhagavad et al. (2008) identified 20 triterpene SAPs from flowers, fruits, seed coats, and seeds of quinoa, but the presence of at least 80 triterpenoid compounds is predicted (Madl et al., 2006). Other Chenopodium species, although closely related, do not contain such a wide variety of SAP structures (Ch. album, Lavaud et al., 2000; Ch. ficifolium, Gohar et al., 2002). Seeds of varieties belonging to the coastal lowlands ecotype of quinoa (Chilean origin) are considered bitter, like the Real varieties (salares ecotype), and they may thus be expected to display an equally high diversity of SAPs (Ward 2000). Indeed, Pu, which exhibited the highest SAP diversity, is a Danish bred variety containing Chilean and Peruvian genetic material. On the other hand, Q124 showed the lowest number of peaks in the SAP profile; this relatively lower SAP diversity may partially account for its sweet feature, possibly due to the absence of SAPs responsible for the bitter taste (Ng et al., 1994). Moreover, Q124 had a 1:1 Ole:Hed ratio, while all bitter varieties had higher relative amount of Hed than Ole. A higher Ole:Hed ratio ( $>$ ca. 2.5 ) is associated with the sweet trait and a low ratio $(<2.5)$ with bitterness (Mastebroek et al., 2000). Meyer et al. (1990) reported that compounds responsible for bitterness in quinoa appear to be a mixture of SAPs whose acidic hydrolysis gave Ole and Hed as the only detectable aglycones by GC/MS analysis; a tetraglycoside of Hed, named quinoside A, was identified as one of these SAPs. Kuljanabhagavad et al. (2008) and Kuljanabhagavad and Wink (2009) reviewed the chemical structures and biological activities of quinoa SAPs, describing the strong relationship between chemical structure of SAPs with their biological activities. Since knowledge regarding the link between biological properties and phytochemistry is, however, still scarce, breeding for quinoas with specific SAP compositions and quantitative structure activity relationship (QSAR) studies will contribute towards understanding this complex issue.

\section{Final remarks}

Quinoa seeds are a highly nutritional food source that is gaining importance worldwide. This has greatly stimulated its cultivation in recent decades and the trend is likely to continue. In addition, there is an urgent need to discover new SAP sources from annual plant species. Quinoa offers a great potential due to the increasing demand for its seeds, combined with the fact that SAPs, present in the seed coat, are discarded and can be regarded as a waste product. The level of SAPs in quinoa is higher than most other species and by considering quinoa SAPs as a waste product with commercial value, we can overcome the problems associated with forest depletion caused by the use of quillay SAPs and with the suboptimal rheological and biocidal properties of triterpene SAPs from other sources. The broad genotypic diversity of quinoa (Ruiz et al., 2014) and, consequently, the diversity in its SAP composition suggests that optimizing the pharmacological, industrial, and agricultural uses of quinoa seed coat SAPs requires a broader and appropriate selection of genotypes. In this study, the diversity and distribution of agro economically important SAPs from an industrial waste material, quinoa seed coats, is reported for the first time.

\section{Acknowledgements}

This research was funded by LATINCROP [KBBE. 2013.3.1 0] EU Latin America Partnering Initiative on Sustainable Biodiversity in Agriculture (EU 7th Framework Programme FP7/2007 2013, EC grant agreement $n^{\circ} 612714$ ) and by BioValue SPIR. University of Bologna No. REP33/2015 and REP54/2016 postdoctoral grants to KBR are grate fully acknowledged.

\section{Appendix A. Supplementary data}

Supplementary data associated with this article can be found, in the online version, at http://dx.doi.org/10.1016/j.indcrop.2017.04.007.

\section{References}

Abugoch, L.E., 2009. Quinoa (Chenopodium quinoa Willd.): composition chemistry, nutritional and functional properties. Adv. Food Nutr. Res. 58, 1-31.

Adolf, V.I., Shabala, S., Andersen, M.N., Razzaghi, F., Jacobsen, S.-E., 2012. Varietal differences of quinoa's tolerance to saline conditions. Plant Soil 357, 117-129.

Ando, H., Chen, Y.C., Tang, H., Shimizu, M., Watanabe, K., Mitsunaga, T., 2002. Food components in fractions of quinoa seed. Food Sci. Technol. Res. 8, 80-84.

Andresen, M., Cedergreen, N., 2010. Plant growth is stimulated by tea-seed extract: a new natural growth regulator? HortScience 45, 1848-1853.

Andresen, M., Wulff, E.G., Mbega, E.R., Stokholm, M.S., Glazowska, S.E., Zida, P.E., Mabagala, R.B., Lund, O.S., 2015. Seed treatment with an aqueous extract of Agave sisalana improves seed health and seedling growth of sorghum. Eur. J. Plant Pathol. 141, 119-132.

Augustin, J.M., Kuzina, V., Andersen, S.B., Bak, S., 2011. Molecular activities, biosynthesis and evolution of triterpenoid saponins. Phytochem 72, 435-457.

Augustin, J.M., Drok, S., Shinoda, T., Sanmiya, K., Nielsen, J.K., Khakimov, B., Olsen, C.E., Hansen, E.H., Kuzina, V., Ekstrøm, C.T., Hauser, T., 2012. UDPglycosyltransferases from the UGT73C subfamily in Barbarea vulgaris catalyze sapogenin 3-O-glucosylation in saponin-mediated insect resistance. Plant Physiol. 160, 1881-1895.

Bazile, D., Jacobsen, S.-E., Verniau, A., 2016. The global expansion of quinoa: trends and limits. Front. Plant Sci. 7. http://dx.doi.org/10.3389/fpls.2016.00622. Christiansen, J.L., Jacobsen, S.-E., Jørgensen, S.T., 2010. Photoperiodic effect on flowering and seed development in quinoa (Chenopodium quinoa Willd.). Acta Agric. Scand. 60, 539-544.

Dini, I., Schettino, O., Simioli, T., Dini, A., 2001a. Studies on the constituents of Chenopodium quinoa seeds: isolation and characterization of new triterpene saponins. J. Agric. Food Chem. 49, 741-746.

Dini, I., Tenore, G.C., Schettino, O., Dini, A., 2001b. New oleanane saponins in Chenopodium quinoa. J. Agric. Food Chem. 49, 3976-3981.

Dini, I., Tenore, G.C., Dini, A., 2002. Oleanane saponins in Kancolla, a sweet variety of Chenopodium quinoa. J. Nat. Prod. 65, 1023-1026.

Fenwick, G.R., Price, K.R., Tsukamoto, C., Okubo, K., 1991. Saponins. In: D’Mello, J.P.F., Duffus, C.M., Duffus, J.H. (Eds.), Toxic Substances in Crop Plants. The Royal Society of Chemistry, Cambridge, pp. 285-327.

Francis, G., Makkar, H.P.S., Becker, K., 2001. Antinutritional factors present in plantderived alternate fish feed ingredients and their effects in fish. Aquaculture 199 197-227.

Gómez-Caravaca, A.M., Iafelice, G., Lavini, A., Pulvento, C., Caboni, M.F., Marconi, E. 2012. Phenolic compounds and saponins in quinoa samples (Chenopodium quinoa Willd.) grown under different saline and non-saline irrigation regimens. J. Agric. Food Chem. 60, 4620-4627.

Gómez-Caravaca, A.M., Iafelice, G., Verardo, V., Marconi, E., Caboni, M.F., 2014. Influence of pearling process on phenolic and saponin content in quinoa (Chenopodium quinoa Willd). Food Chem. 157, 174-178.

Güclü-Üstündağ, O., Mazza, G., 2007. Saponins: properties, applications and processing. Crit. Rev. Food Sci. Nutr. 47, 231-258.

Gohar, A.A., Maatooq, G.T., Niwa, M., Yoshiaki, T., 2002. A new triterpene saponin from Chenopodium ficifolium. Z. Naturforschung C A 57, 597-602.

Jacobsen, S.-E., 1998. Developmental stability of quinoa under European conditions. Ind. Crop Prod. 7, 169-174.

Jacobsen, S.-E., 2003. The worldwide potential for quinoa (Chenopodium quinoa Willd.). Food Rev. Int. 19, 167-177.

Jacobsen, S.E., 2015. Adaptation and scope for quinoa in northern latitudes of Europe. In: Bazile, D., Bertero, H.D., Nieto, C. (Eds.), State of the Art Report on Quinoa Around the World in 2013. FAO \& CIRAD, Rome, pp. 436-446.

Jarvis, D.E., Ho, Y.S., Lightfoot, D.J., Schmöckel, S.M., Li, B., Borm, T.J.A., et al., 2017. The genome of Chenopodium quinoa. Nature 542, 307-312.

Khakimov, B., Amigo, J.M., Bak, S., Engelsen, S.B., 2012. Plant metabolomics: resolution and quantification of elusive peaks in liquid chromatography-mass spectrometry profiles of complex plant extracts using multi-way decomposition methods. J. Chromatogr. A 1266, 84-94.

Khakimov, B., Motawia, M.S., Bak, S., Engelsen, S.B., 2013. The use of trimethylsilyl cyanide derivatization for robust and broad-spectrum high-throughput gas chromatography-mass spectrometry based metabolomics. Anal. Bioanal. Chem. 405, 9193-9205. 
Khakimov, B., Mongi, R.J., Sørensen, K.M., Ndabikunze, B.K., Chove, B.E., Engelsen, S.B., 2016a. A comprehensive and comparative GC-MS metabolomics study of nonvolatiles in Tanzanian grown mango, pineapple, jackfruit, baobab and tamarind fruits. Food Chem. 213, 691-699.

Khakimov, B., Tseng, L.H., Godejohann, M., Bak, S., Engelsen, S.B., 2016b. Screening for 1614.

triterpenoid saponins in plants using hyphenated analytical platforms. Molecules 21,

Kubo, I., Matsumoto, A., 1984. Secreted oleanolic acid on the cuticle Olea europaea

(Oleaceae); a chemical barrier to fungal attack. Cell. Mol. Life Sci. 40, 937-938. Kuljanabhagavad, T., Wink, M., 2009. Biological activities and chemistry of saponins from Chenopodium quinoa Willd. Phytochem. Rev. 8, 473-490.

Kuljanabhagavad, T., Thongphasuk, P., Chamulitrat, W., Wink, M., 2008. Triterpene saponins from Chenopodium quinoa willd. Phytochemistry 69, 1919-1926.

Lavaud, C., Voutquenne, L., Bal, P., Pouny, I., 2000. Saponins from Chenopodium album. Fitoterapia 71, 338-340.

Lazo-Vélez, M.A., Guajardo-Flores, D., Mata-Ramírez, D., Gutiérrez-Uribe, J.A., SernaSaldivar, S.O., 2016. Characterization and quantitation of triterpenoid saponins in raw and sprouted Chenopodium berlandieri spp. (Huauzontle) grains subjected to germination with or without selenium stress conditions. J. Food Sci. 81, C19-C26. http://dx.doi.org/10.1111/1750-3841.13174.

Madl, T., Sterk, H., Mittelbach, M., Rechberger, G.N., 2006. Tandem mass spectrometric analysis of a complex triterpene saponin mixture of Chenopodium quinoa. J. Am. Soc.

Mass Spectrom. 17, 795-806.

Maradini, A.M., Pirozi, M.R., Da Silva, J.T., Pinheiro, H.M., Paes, J.B., Dos Reis, J.S., 2015. Quinoa: nutritional, functional and antinutritional aspects. Crit. Rev. Food Sci. Nutr. http://dx.doi.org/10.1080/10408398.2014.1001811.

Mastebroek, H.D., Limburg, H., Gilles, T., Marvin, H.J.P., 2000. Occurrence of sapogenins in leaves and seeds of quinoa (Chenopodium quinoa Willd.). J. Sci. Food Agric. 80,

$152-156$.

Medina-Meza, I.G., Aluwi, N.A., Saunders, S.R., Ganjyal, G.M., 2016. GC-MS profiling of triterpenoid saponins from 28 quinoa varieties (Chenopodium quinoa Willd.) grown in Washington State. J. Agric. Food Chem. 64, 8583-8591.

Meyer, B.N., Heinstein, P.F., Burnouf-Radosevich, M., Delfel, N.E., McLaughlin, J.L., 1990. Bioactivity-directed isolation and characterization of quinoside A: one of the toxic/bitter principles of quinoa seeds (Chenopodium quinoa Willd.). J. Agric. Food Chem. 38, 205-208.

Miranda, M., Delatorre-Herrera, J., Vega-Gálvez, A., Jorquera, E., Quispe-Fuentes, I., Martínez, E.A., 2014. Antimicrobial potential and phytochemical content of six diverse sources of quinoa seeds (Chenopodium quinoa Willd.). Agric. Sci. 5, 1015-1024.

Mizui, F., Kasai, R., Ohtani, K., Tanaka, O., 1990. Saponins from the bran of quinoa, Chenopodium quinoa Willd. II. Chem. Pharm. Bull. 38.

Ng, K.G., Price, K.R., Fenwick, G.R., 1994. A TLC method for the analysis of quinoa (Chenopodium quinoa) saponins. Food Chem. 49, 311-315.

Pollier, J., Goossens, A., 2012. Oleanolic acid. Phytochemistry 77, 10-15.

Potter, D.A., Redmond, C.T., Meepagala, K.M., Williams, D.W., 2010. Managing earthworm casts (Oligochaeta: lumbricidae) in turfgrass using a natural byproduct of

tea oil (Camellia sp.) manufacture. Pest Manage. Sci. 66, 439-446.

Price, K.R., Johnson, I.T., Fenwick, G.R., Malinow, M.R., 1987. The chemistry and biological significance of saponins in foods and feeding stuffs. Crit. Rev. Food Sci. Nutr. 26, 27-135

Qin, F., Ye, Y.P., Sun, H.X., 2006. Haemolytic activity and adjuvant effect of notoginsenoside $\mathrm{K}$ from the roots of Panax notoginseng. Chem. Biodivers. 3, 1144-

1152.

Repo-Carrasco, R., Espinoza, C., Jacobsen, S.-E., 2003. Nutritional value and use of the Andean crops quinoa (Chenopodium quinoa) and kañiwa (Chenopodium pallidicaule). Food Rev. Int. 19, 179-189.

Ridout, C.L., Price, K.R., Dupont, M.S., Parker, M.L., Fenwick, G.R., 1991. Quinoa saponins-analysis and preliminary investigations into the effects of reduction by processing. J. Sci. Food Agric. 54, 165-176.

Rubio-Tapia, A., Kyle, R.A., Kaplan, E.L., Johnson, D.R., Page, W., Erdtmann, F., Brantner,
T.L., Kim, W.R., Phelps, T.K., Lahr, B.D., Zinsmeister, A.R., 2009. Increased prevalence and mortality in undiagnosed celiac disease. Gastroenterology 137 , 88-93.

Ruiz, K.B., Biondi, S., Oses, R., Acuña-Rodríguez, I.S., Antognoni, F., Martinez-Mosqueira, E.A., Coulibaly, A., Canahua-Murillo, A., Pinto, M., Zurita-Silva, A., Bazile, D., Jacobsen, S.-E., Molina-Montenegro, M.A., 2014. Quinoa biodiversity and sustainability for food security under climate change. A review. Agron. Sust. Dev. 34, 349-359.

Ruiz, K.B., Aloisi, I., Del Duca, S., Canelo, V., Torrigiani, P., Silva, H., Biondi, S., 2016. Salares versus coastal ecotypes of quinoa: salinity responses in Chilean landraces from contrasting habitats. Plant Physiol. Biochem. 101, 1-13.

San Martín, R., Ndjoko, K., Hostettmann, K., 2008. Novel molluscicide against Pomacea canaliculata based on quinoa (Chenopodium quinoa) saponins. Crop Prot. 27, 310-319.

San Martín, R., 2000. Sustainable production of Quillaja saponaria Mol. saponins. Oleszek, W., Marston, A. (Eds.), Saponins in Food, Feedstuffs and Medicinal Plants, Proceedings of the Phythochemical Society of Europe 45, 271-279.

Schlotterbeck, T., Castillo-Ruiz, M., Cañon-Jones, H., San Martín, R., 2015. The use of leaves from young trees of Quillaja saponaria (Molina) plantations as a new source of saponins. Econ. Bot. 69, 262-272.

Sparg, S.G., Light, M.E., van Staden, J., 2004. Biological activities and distribution of plant saponins. J. Ethnopharmacol. 94, 219-243.

Stikic, R., Glamoclija, D., Demin, M., Vucelic-Radovic, B., Jovanovic, Z., MilojkovicOpsenica, D., Jacobsen, S.-E., Milovanovic, M., 2012. Agronomical and nutritional evaluation of quinoa seeds (Chenopodium quinoa Willd.) as an ingredient in bread formulations. J. Cereal Sci. 55, 132-138.

Stuardo, M., San Martín, R., 2008. Antifungal properties of quinoa (Chenopodium quinoa Willd) alkali-treated saponins against Botrytis cinerea. Ind. Crops Prod. 27, 296-302.

Sumner, L.W., Amberg, A., Barrett, D., Beale, M.H., Beger, R., Daykin, C.A., Fan, T.W.M., Fiehn, O., Goodacre, R., Griffin, J.L., Hankemeier, T., 2007. Proposed minimum reporting standards for chemical analysis. Metabolomics 3, 211-221.

Sun, H.X., Pan, H.J., Pan, Y.J., 2003. Haemolytic activities and immunologic adjuvant effect of Panax notoginseng saponins. Acta Pharmacol. Sin. 24, 1150-1154.

Szakiel, A., Grzelak, A., Dudek, P., Janiszowska, W., 2003. Biosynthesis of oleanolic acid and its glycosides in Calendula officinalis suspension culture. Plant Physiol. Biochem. 41, 271-275.

Szakiel, A., Pączkowski, C., Henry, M., 2011. Influence of environmental abiotic factors on the content of saponins in plants. Phytochem. Rev. 10, 471-491.

Vega-Gálvez, A., Miranda, M., Vergara, J., Uribe, E., Puente, L., Martínez, E.A., 2010. Nutrition facts and functional potential of quinoa (Chenopodium quinoa Willd.): an ancient Andean grain: a review. J. Sci. Food Agric. 90, 2541-2547.

Verza, S.G., Silveira, F., Cibulski, S., Kaiser, S., Ferreira, F., Gosmann, G., Roehe, P.M. Ortega, G.G., 2012. Immunoadjuvant activity, toxicity assays, and determination by UPLC/Q-TOF-MS of triterpenic saponins from Chenopodium quinoa seeds. J. Agric. Food Chem. 60, 3113-3118.

Vincken, J.P., Heng, L., de Groot, A., Gruppen, H., 2007. Saponins, classification and occurrence in the plant kingdom. Phytochemistry 68, 275-297.

Ward, S.M., 2000. Response to selection for reduced grain saponin content in quinoa (Chenopodium quinoa Willd.). Field Crops Res. 68, 157-163.

Woldemichael, G.M., Wink, M., 2001. Identification and biological activities of triterpenoid saponins from Chenopodium quinoa. J. Agric. Food Chem. 49 2327-2332.

Yoshiki, Y., Kudou, S., Okubo, K., 1998. Relationship between chemical structures and biological activities of triterpenoid saponins from soybean. Biosci. Biotechnol. Biochem. 62, 2291-2299.

Zhu, N., Sheng, S., Sang, S., Jhoo, J.-W., Bai, N., Karwe, M.V., Rosen, R.T., Ho, C.-T., 2002. Triterpene saponins from debittered quinoa (Chenopodium quinoa) seeds. J. Agric. Food Chem. 50, 865-867.

Zurita-Silva, A., Fuentes, F., Zamora, P., Jacobsen, S.-E., Schwember, A., 2014. Breeding quinoa (Chenopodium quinoa Willd.): potential and perspectives. Mol. Breed. 34, 13-30. http://dx.doi.org/10.1007/s11032-014-0023-5. 